\title{
The social aspects of alcohol misuse/abuse in South Africa
}

\author{
a Setlalentoa BMP, MA $\quad$ 'Pisa PT, PhD a Thekisho GN, MA cRyke EH, PhD bod Loots Du T, MSc, PhD \\ ${ }^{a}$ Department of Social Work, North-West University, Mafikeng Campus, Mmabatho, South Africa ${ }^{b}$ Centre of Excellence for Nutrition, North-West University, \\ Potchefstroom Campus, South Africa ' Department of Psychosocial Behavioural Sciences, North-West University, Potchefstroom Campus, South Africa. \\ ${ }^{\mathrm{d}}$ Centre for Human Metabonomics, School of Physical and Chemical Sciences, Potchefstroom 2520, South Africa \\ Correspondence to: Dr Pedro T Pisa, e-mail: 20369190@nwu.ac.za/pedropisa2005@yahoo.com \\ Keywords: Social aspects, psychological aspects, alcohol misuse/abuse, South Africa, urbanisation
}

\section{Abstract}

Use of alcohol in Africa, particularly in South Africa, has a long history and is a way of life for many people, regardless of their socio-economic background. Alcohol abuse has many negative economic, social and health consequences. The objective of this review is to present in brief the history of alcohol use and the social and economic causes and consequences of alcohol abuse in South Africa. Research has shown that the socio-economic effects associated with alcohol abuse include unemployment, violence, crime, sexual risk behaviour and disruptions to family life and work performance. These effects are discussed by emphasising that social and economic changes stemming from urbanisation account for new patterns of drinking among most Africans. South African legislation pertaining to alcohol is also discussed in order to highlight the need for changing or amending certain acts if alcohol abuse is to be reduced.

(D) Peer reviewed. (Submitted: 2009-08-12, Accepted: 2009-08-22). @ SAJCN

S Afr J Clin Nutr 2010;23(3)(Supplement 1):S11-S15

\section{Introduction}

Alcohol plays a major role in the lives of many South Africans. Besides having significant direct and indirect effects on health and nutrition, it also affects social and economic aspects of the South African community. Traditionally, in rural areas, alcohol served many purposes. Not only was it used as a means of payment and of strengthening friendship, but beer was also associated with manhood and with the strengthening of the body. ${ }^{1}$ Similarly, in other African communities such as Kenya, alcohol was used to celebrate important occasions such as marriages and success in harvests. Drinking was moderated and subjected to certain guidelines as to when, how much, why and who should drink. Alcohol was mainly for domestic consumption. ${ }^{2}$

With the arrival of the European farmers and traders in the 1800s there was a move by Africans to drink European liquor, called "Cape Smoke". This was highly unacceptable to many farmers because they believed alcohol made Africans disobedient. ${ }^{1}$ Apparently, the disobedience was displayed when workers were under the influence of liquor and would not take orders, would absent themselves from work or even talk back, which farmers found unacceptable. This led to many new laws in the 1900s that controlled drinking, mostly by Africans. One of the controlling measures was the introduction of beer halls around 1908, which seemed to be based on the idea that it was wrong for the "natives" to have their own beer hall. ${ }^{1}$ The proliferation of illegal shebeens increased during this time, ultimately leading to unmonitored drinking patterns and abuse. One could argue that the prohibitions resulted in Africans wanting and finding ways of acquiring more of both home-brewed and European liquor (brandy). These are some of the factors that led to the misuse of alcohol, because people would have to consume more because there was no guarantee that they would get a drink again.
African beer was fermented from locally grown foods such as sorghum and maize. This kind of beverage took about four to 14 days to brew. In some other parts of sub-Saharan Africa the alcoholic beverages available were fermented honey water, fermented fruits and juices, fermented sap of various species of palm, and beers. The brewing of alcohol had economic spin-offs for women who sold it as a way of supplementing the meagre wages their husbands were earning. In order to meet the high demand, people tried different ways of brewing beer easily and quickly, often compromising quality. This is how "concoctions" started, most of which were brewed in less than a day. ${ }^{3}$ It was a time during which South Africa as a country was entering an industrial age that led to a change in the traditional use of alcohol.

With the coming of Dutch Settlers, and later the French Huguenots, to the Cape as wine farmers from around 1652 onwards, the labour force comprised mainly Africans. In addition to their salary, labourers were given wine. This system became known as the "tot" or "dop" system. ${ }^{1,4,5}$ Through this system heavy drinking became entrenched in the lives of workers and their families for generations. ${ }^{6}$ Alcohol was used by the colonisers as a mechanism to seize power - a form of political, economic and socio-cultural domination. ${ }^{7}$ These were micro-level practices that went unchecked. Since the "dop" system was mostly used in the Western Cape, the system has even managed to perpetuate racial stereotypes and inferences that the problem of over-drinking is biologically determined and not socially constructed. ${ }^{8}$ The "dop" system was formally outlawed by the South African government in 1961, though its effects still linger. In more recent years it has taken a variety of forms, including that of a "gift" or supplement to remuneration, or as alcohol provided on credit. ${ }^{9}$ Currently, there are still traces of the earlier problems. People are exposed to misuse and abuse that could be traced to the drinking patterns of the 1600 s. Parry and Bennets, ${ }^{8}$ in their study among South Africans, found significant consumption differences by population 
group and gender with intake higher in urban than in rural areas, more alcohol consumed by individuals aged between 35 and 44 and 45 and 54 , and a seemingly high rate of misuse over weekends. Similar trends were also observed in countries such as Kenya. ${ }^{10}$ This review forms part of a series of articles ${ }^{11-14}$ that examines the role of alcohol in South African society. A holistic, integrated approach is followed, focusing on the metabolism of alcohol, ${ }^{11}$ the health consequences of consumption of alcoholic beverages ${ }^{11-14}$ and the social aspects of alcoholic misuse/abuse, the major objective of this article.

From a nutritional point of view, alcohol abuse is a major cause of malnutrition. The reasons are threefold. Firstly, alcohol affects the mechanisms that regulate appetite and food intake, causing the intake of food among alcohol abusers to decrease. Alcohol inhibits the breakdown of nutrients into usable molecules by decreasing the secretion of the necessary digestive enzymes, causing nutrient absorption to decrease. Alcohol also damages the cells lining the stomach and intestines, further disturbing the digestive system and absorption. ${ }^{15}$ Secondly, alcohol is rich in energy, but like many other pure sugars, most alcoholic beverages are empty of nutrients. Therefore, chronic alcohol ingestion causes primary malnutrition by displacing other dietary nutrients. ${ }^{16,17}$ It is important to note that although ethanol is rich in energy, its chronic consumption does not produce a directly proportional gain in body weight. This may be attributed to damaged mitochondria and the resulting poor coupling of fat oxidation metabolically with energy production. ${ }^{16,17}$ Thirdly, alcohol abuse is associated with gastrointestinal and liver complications, ultimately interfering with digestion, absorption, metabolism and the activation of nutrients, thereby causing secondary malnutrition. ${ }^{15,18}$

There is agreement that among populations in the Western world, moderate alcohol consumption is associated with better cardiovascular health and longevity..$^{19}$ Alcohol is a central nervous system depressant. It acts on many sites, including the reticular formation, spinal cord, cerebellum and cerebral cortex, and on many neurotransmitters. Increased turnover of norepinephrine and dopamine in the brain is responsible for the sensations of pleasure and relaxation. ${ }^{20}$

Because this review is limited to discussing the causes and consequences of alcohol abuse in South Africa from a social and economic perspective, a very brief summary of the relationships between alcohol abuse and malnutrition is given below to put this article in the context of the series of articles mentioned earlier.

The most common factors leading to alcohol abuse in South Africa are modernisation and urbanisation, high-risk and stressful jobs, availability, and cultural beliefs. These and other factors are discussed below.

\section{Modernisation and urbanisation}

Rapid social and economic changes stemming from urbanisation account for new patterns of drinking in most African settings. The emerging patterns are often not built upon traditional drinking behaviours where there was social control. Instead these are influenced by factors such as easy access to alcohol, which has a higher ethanol content, as well as vigorous advertising in the media, which disregards traditional constraints on when alcohol may be consumed, by whom and where. ${ }^{8}$ Jernigan et a ${ }^{21}$ explain a pattern where people used to drink until "the beer ran out", but this is being radically replaced by a pattern of drinking "until the money runs out".
As Willis ${ }^{22}$ asserts, alcohol consumption is highly commoditised, and is no longer restricted to adults or to certain restricted occasions.

The traditional culture of drinking, which seemed to have been obtained and determined by "proper" drinking patterns, appears to be eroded and replaced by multiple drinking cultures that vary from one community to the other. Most of these drinking cultures openly challenge earlier ideas of temperance, age and gender restrictions. Migration has also contributed to this problem. Urbanisation appears to have impacted negatively on rural areas as some of the urban ways disperse back to them. For instance, traditional home-brewed beverages, known for their nutritional value, have been replaced by deadly concoctions that pose a health hazard. ${ }^{22}$

\section{High-risk and stressful jobs}

Although characteristics and properties endemic to certain occupations may shape workers' alcohol use, explanations of alcohol abuse rarely take into account the impact of the occupational setting. ${ }^{23}$ Roman $^{24}$ found that workers with mobility and task independence at work are more prone to alcoholism. While there are contradictory and inconclusive results concerning the direct effects of specific job and occupational characteristics on alcohol abuse by workers, researchers are unequivocal in their findings that negative work experiences often lead to problem drinking. ${ }^{25}$ No field of occupation is exempted from the negative effects of alcohol abuse, yet the following are identified as some of the highrisk and stressful jobs that predispose workers to alcohol misuse: working in the brewing and distilling industry, as hoteliers and barmen/-women, in the armed services and the police in particular. ${ }^{26}$ The alcohol industry happens to be a major source of employment. ${ }^{8}$ Risk is caused by the availability of alcohol, high levels of responsibility and performance anxiety, alertness, as well as stress. In the South African Police Service, stressors range from violence that is endemic in the country, to high crime levels, emotional strain caused by organisational transformation, lack of resources, bureaucracy and family responsibilities. ${ }^{27}$ Risky drinking in these high-risk and stressful jobs is mainly to cope with social pressure and as an escape from reality, a form of "letting off steam".

\section{Availability}

One of the causes of alcohol abuse and misuse is its availability in terms of location, time and affordability. In 1997 in South Africa there were about 22900 licensed outlets, including liquor stores, restaurants, taverns and supermarkets, compared to about 20000 informal liquor outlets, such as shebeens, which are mostly unregulated and operate outside the confines of the law. After nearly a decade these outlets have multiplied. ${ }^{8}$ The South African Liquor Act of $2003^{28}$ regulates the times when liquor may be traded. However, outlets such as supermarkets and taverns trade at different times than bottle stores. Some of the unregulated outlets operate according to demand. The age restriction is known to be 18 years and this information is displayed in bottle stores and supermarkets, but there are no proper measures to ensure that it is adhered to. This makes alcohol easily and widely available and affordable to all races, genders and ages, despite the restrictions.

\section{Cultural beliefs}

Traditionally it was not acceptable for native African women to drink alcohol. This view is supported by Mphi, ${ }^{29}$ who asserts that women 
in Lesotho are not allowed to drink alcohol at all, despite the fact that many are brewers and traders of traditional beer. A woman who indulges in alcohol is subject to derision, condemnation and even divorce. In colonial Zimbabwe, men even fought against what they termed "joint drinking", that is, women and men drinking together at the municipal beer halls. ${ }^{30}$ The danger of such traditions is that they tend to compel women to drink in private, which can produce hazardous results in public.

These inhibiting cultural practices are entrenched through socialisation in most South African communities. In Western culture such inhibitions appear to be absent. Both men and women from all socio-economic backgrounds are allowed to enjoy their alcohol intake in public places. ${ }^{8}$ Young African women tend to emulate this behaviour, presumably because of the influence of urbanisation and acculturation. Based on the findings of the Department of Health's South African Demographic and Health Survey (SADHS) conducted in 1998, the majority of risky weekend drinkers are African women $(42.1 \%)$ and their age range is between 15 and 24 years $(30.1 \%) .{ }^{31}$ Morojele et $\mathrm{a}^{32}$ in their study on alcohol use and sexual behaviour among risky drinkers in Gauteng province, South Africa, revealed gender differences in that men's drinking is traditionally and currently accepted as pleasure, recreational and sensation-seeking. Their drinking is encouraged by their peers, and heavy drinking symbolises masculinity. Such behaviours perpetuate binge drinking.

\section{Children living on the street}

Although it is widely recognised that drug and alcohol misuse is associated with homelessness, there is debate and speculation about whether problematic alcohol use is a cause or consequence of youth homelessness. ${ }^{33}$ Homelessness and alcohol use have similar root causes, namely stress at home and school. Family conflict, violence and abuse are critical factors for both experiences. In a study conducted in Australia, one-quarter of the sample under investigation indicated that familial drug and alcohol use was the critical factor that resulted in them leaving home. ${ }^{34}$ Clearly a gap exists in our knowledge about the relationship between young people's alcohol use and their pathways into homelessness.

As pointed out by Maree ${ }^{35}$ children living on the street constitute one of the fastest growing problems in Africa. Children live on the streets for a variety of reasons. Some would do so as an escape from reality or as a coping mechanism because of family disorganisation, divorce, poverty, loneliness, boredom, unemployment and crime. South Africa is equally plagued by this problem of children leaving home to live on the streets. ${ }^{36}$ Curiosity, delinquency and peer pressure also play a role. Because they live on the streets far from their parents, they have no boundaries to guide their behaviour. This is why they start sniffing glue, smoking dagga, using other drugs and using and misusing alcohol.

Based on these causes, people tend to be affected psychologically and socially.

\section{Psychological effects}

Alcohol abuse and misuse could lead to stress and anxiety. This could cause individuals to increase their dosage in order to cope with their problematic situations, only to experience the same disillusionment when the effects wear off. People experience depression for various reasons. Bezuidenhout ${ }^{37}$ states that some people may experience stress and anxiety because of alcohol abuse. It could be because of personal problems or failure to control their drinking. If not attended to, he or she might commit suicide. ${ }^{34}$ The findings of research undertaken by the Medical Research Council show that one in four of those who have committed suicide in South Africa, were over the blood alcohol limit of $0.05 \mathrm{~g} / 100 \mathrm{ml} .^{38}$ Chronic stress caused by alcohol abuse was also found to be related to youth suicide. ${ }^{39}$ Some adolescents become aware of the adverse effects of alcohol and try to stop drinking but more often than not, they fail to do so, especially without professional help, and consequently resort to suicide.

\section{Social effects}

\section{Unemployment}

Alcohol abuse at the workplace potentially lowers productivity. Absence for sickness associated with abuse and dependence entails a substantial cost to employers and social security systems. Ample evidence has demonstrated an association between alcohol abuse and unemployment. ${ }^{38}$ The causal association may go in either direction. Heavy drinking may lead to unemployment, but loss of work may also result in increased drinking. ${ }^{40}$ South Africa is plagued by a high unemployment rate. A Statistics South Africa report in September $2006^{41}$ indicated that 4391000 people were unemployed, 12815000 were not economically active and 3217000 were discouraged work seekers (unemployed but had not taken steps to find work or start a business in the four weeks prior to the interview). Unemployed people may drink to escape reality and to cope with the harsh situations they find themselves in. These views are supported by Ettner, ${ }^{42}$ whose results provided literature evidence that a recessionary environment or lay-offs resulting from harsh environmental regulation will increase alcohol abuse. Poverty as one of the end results of unemployment is at a high level in South Africa. It is to be noted that communities living below the poverty datum line tend to spend the little money they have on alcohol. ${ }^{38}$

\section{Violence and crime}

Alcohol abuse has been shown to be a significant risk factor for domestic violence, although the relationship is complex. ${ }^{38}$ Drinking has frequently also been associated with intra-family violence. Evidence suggests a strong association between abuse and marital violence, but that violence rates vary based on research design, methodologies and samples. ${ }^{38}$

A study conducted in Nigeria showed a significant relationship between violence and alcohol use. Alcohol use was involved in 51\% of the cases in which a husband stabbed a wife. ${ }^{43}$ In a 1998 South African cross-sectional study of violence against women undertaken in three provinces, it was found that domestic violence was significantly positively correlated with the women drinking alcohol and conflict over the partner's drinking. ${ }^{44}$

It is stated that alcohol is present in offenders and victims in many violent events. The results of Phase 3 of the 3-Metros (Cape Town, Durban and Gauteng) Arrestee Study, conducted during August/ September 2000 in South Africa, showed a high level of drug use, including alcohol use among arrestees. Over all sites, $50 \%$ or more of people arrested for the following crimes tested positive for at least one drug: drug and alcohol offences (75\%), housebreaking (66\%), motor vehicle theft $(59 \%)$ and rape $(50 \%) .{ }^{45}$ Exposure to violence and alcohol is identified as one of the developmental factors that contribute to violence. Withdrawal symptoms can develop into aggressive behaviour towards family members, friends or members 
of the community. These violent behaviours often result in sexual assault. ${ }^{46,47}$

\section{Sexual risk behaviour}

A study conducted by Morojele et $\mathrm{a}^{32}$ confirms that heavy alcohol consumption is a major health concern in South Africa and that there is a link between alcohol consumption and sexual risk behaviour. The study also revealed that there were high levels of alcohol consumption and unprotected sex among people who engaged in casual relationships. Alcohol use is prevalent in South Africa and alcohol use may be associated with higher risk for human immunodeficiency virus (HIV) transmission. Olley et al ${ }^{48}$ argued that some HIV-infected individuals, despite knowledge of their status, continue to practise unsafe sex, which places them and their partners at considerable risk. A partner who is under the influence of alcohol could be at risk because of such practices. According to the 2004 report by the Medical Research Council of South Africa, more than five million South Africans out of a total of forty-six million were HIV infected. ${ }^{49}$ Kalichman et a ${ }^{50}$ confirmed the association between alcohol use and HIV-risk-related behaviour among 134 men and 92 women receiving sexually transmitted infection (STI) clinic services in Cape Town, South Africa. The study concluded that the association between alcohol use and sexual risk behaviours in a population at high risk for HIV transmission demonstrates the need for integrating alcohol risk-reduction counselling with HIV-prevention counselling among STI clinic patients in South Africa.

The 2004 report by the Medical Research Council of South Africa further indicates that 37000 children were infected with the HIV virus at or around birth (through vertical transmission) and 26000 were infected through breastfeeding. One-quarter to one-third of the vertically infected children died before they reached one year of age ${ }^{49} \mathrm{HIV} /$ AIDS aggravates already existing poverty, especially when breadwinners lose their jobs because of ill health or death. In South Africa there were approximately 3.3 million orphans by 2004 . Almost two-thirds of the orphaned children lived in households headed by children as young as 13 years of age. Poverty, ill health, teenage pregnancy, delinquency and alcohol and drug abuse are common occurrences in such homes. ${ }^{49}$

\section{Family disruption}

The function of a family as a system is to provide shelter as well as emotional, economic and psychological support. But when one member abuses alcohol, the family becomes destabilised or the balance is affected. Alcohol abuse tends to retard the efforts of a family to maintain its balance. Money that should be used for the family is misused on alcohol and this could contribute to violence and poverty. Relationships are affected because the perpetrator is under the influence of alcohol and is not able to love and care. A 1998 cross-sectional study on violence against women was undertaken in three South African provinces. This study showed how domestic violence was significantly (positively) associated with alcohol abuse..$^{38}$ Lack of parental control due to the fact that parents do not provide clear boundaries could lead to disarray in the family and alcohol abuse. It exposes children to anti-social behaviours, since parents become negative role models. ${ }^{36,37}$

Excessive intake of alcohol could also lead to divorce, affecting the partners, who have to go through emotionally traumatic experiences and adjustments, which could be social, economic and sexual, as well as children, who might have difficulty in dealing with divorce.
They could be confronted with the necessity of social, psychological, educational and economic adjustment. ${ }^{37}$ Abuse of alcohol also affects social networks. A network can provide supportive environmental help as well as instrumental help. It provides sources for human relationships, recognition, affirmation and emotional support. ${ }^{51}$ Social networks such as kin, friends, neighbours, extended family, work mates and acquaintances are affected by divorce as well. The divorced are at risk of social and/or emotional isolation and stigma. Social isolation is loneliness as a result of a distance they do not choose, or when they are without a social network. This could worsen the problem of alcohol abuse.

\section{Work performance}

Any working environment has certain expectations of its employees. They have to be productive in order for the company to realise profits. Those employees who abuse alcohol are not likely to perform well. Some of the problems identified are absenteeism, low production (inability to meet deadlines, inability to follow procedures) and proneness to job-related accidents. This could lead to dismissal that would affect the person and his or her family. ${ }^{8}$ More employee assistance programmes should be introduced to deal with alcoholism that affects job performance. Enhanced production cannot be achieved if people have psycho-social problems because people cannot be separated from their environment.

\section{Economic cost and injuries}

The annual economic cost of alcohol misuse in South Africa could range between $0.5 \%$ and $1.9 \%$ of the gross domestic product (GDP). These figures are based on the utilisation of a middle-of-the-range estimate that considers costs associated with treatment, trauma, mortality and crime, which is about $1 \%$ of GDP. This translates to about R8.7 billion per year, an amount almost twice exceeding that received in excise duties on alcoholic beverages in the period 2000/01. ${ }^{52}$ Motor vehicle crashes in the country also account for approximately 11 deaths per 100 million kilometres travelled. Traffic crashes that involve pedestrians account for about $40 \%$ of annual mortality on the roads in South Africa. Alcohol abuse and poor roads are cited as the main contributing factors..$^{53}$

\section{Legislation on alcohol}

The Department of Social Development is South Africa's leading government institution in combating alcohol and drug abuse. The vision of a society free from the abuse of alcohol and other forms of drugs is the driving force behind the introduction of various policies in the country. Some of these include the Liquor Act of 2003, which covers all relevant aspects including the production, distribution and consumption of alcohol and the Prevention and Treatment of Drug Dependency Act of 1992, which provides for the establishment of a central drug authority, the development of programmes and the establishment and management of treatment centres. The revised National Drug Master Plan 2005-2010 spells out strategic objectives to guide service providers in their provision of relevant and appropriate services. The strategies outlined in the policy include prevention, early intervention, treatment, aftercare and reintegration. In addition, the policies also include communitybased intervention, capacity building, management of treatment practices and information management. International collaboration forms an integral part of the policies as South Africa sees the need to join the global fight against alcohol and drug abuse..$^{52}$ Gaps in the implementation and monitoring of these policies have been evident. 
However, a concerted effort by all remains the obvious route to victory over the scourge of alcohol abuse and misuse.

The taxation of liquor also serves as a restrictive measure. A word of caution from Parry and Bennets 8 is that the taxes should not be so huge as to promote the possibility of smuggling alcohol from neighbouring states or driving consumers towards unhygienic concoctions. In terms of cultural intervention, religion seems to contribute to abstinence. A typical example is of people who follow Islamic teachings, which forbid alcohol intake. Most Africans are also socialised to reserve the drinking of alcohol for adults.

\section{Discussion and conclusion}

Historically, alcohol consumption contributed towards the strengthening of the socio-cultural fibre of African communities. Alcohol was regulated by social rules and used in moderation. ${ }^{1}$ However, with time the pattern changed. The use of alcohol today poses a major threat to the quality of life of many South Africans, ultimately causing detrimental public health effects as well as negative socio-economic effects on the country. Alcohol misuse/ abuse has become an everyday reality that directly or indirectly impairs peoples' lives, not only individually, but also on familial, societal and national levels. ${ }^{8}$

One of the most important public health and social issues facing South Africa is how to deal effectively and compassionately with people and communities who are struggling due to alcohol abuse. Although significant achievements have been noted in the policy and legislative domain, the impact does not seem to match the extent of the disruption caused by alcohol abuse. There is an urgent need to re-address these policies and strategies to combat abuse. Moderate alcohol consumption has been shown to have significant health benefits ${ }^{54}$ but the disruption caused by alcohol abuse on different societal levels, ranging from family breakdown to crime, remains overwhelming. This presents policy makers in South Africa with the dilemma of whether to encourage moderate consumption of alcohol or promote total abstinence.

The Food-Based Dietary Guidelines for South Africa do not clearly stipulate how much alcohol should be consumed in order to retain the proposed health benefits attributed to moderate use of alcohol. There are indications that the African population is increasingly prone to alcohol dependency, due to abuse. It seems necessary to define moderate drinking in no uncertain terms. Besides the current policies put in place to curb alcohol abuse, a systematic programme for monitoring and evaluating the impact of these policies should be established. In conclusion, there is a need for policy makers to weigh the scientific findings that show the health benefits of light/moderate consumption of alcohol and the destructive effects of abuse before championing the way forward for this population. After such an exercise, the Food-Based Dietary Guidelines concerning alcohol use for South Africans ${ }^{55}$ might have to be revised.

\section{References}

1. La Hausse P. Brewers, beer halls and boycotts. A history of liquor in South Africa. Johannesburg: Ravan Press; 1988

2. Nielson MFJ, Resnick CA, Acuda SW. Alcoholism among outpatients of a rural district general hospital in Kenya. Br J Addict. 1989;84:1343-1351.

3. Adelekan ML. Substance use, HIV infection and the harm reduction approach in sub-Saharan Africa. Int J Drug Policy 1998;9:315-323.

4. D'Souza VP. These grapes aren't sour. The New York Amsterdam News 2003 November 27 - December D'Souza

5. McKinstry J. Using the past to step forward: Fetal alcohol syndrome in the Western Cape province of South Africa. Am J Psychol. 2005;95(7):1097-1099.

6. May PA, Gossage JP, Brooke LE, et al. Maternal risk factors for fetal alcohol syndrome in the Western
Cape province of South Africa: A population-based study. Am J Public Health 2005;95(7):1190-1199. Schler L. Looking through a glass of beer: Alcohol in the cultural spaces of colonial Douala, 1910-1945. Int J Afr Hist Stud. 2002:35(2-3):315-334.

8. Parry C, Bennets A. Alcohol policy and public health in South Africa. Cape Town: Oxford University Press; 1998.

9. London L. Alcohol consumption amongst South African farm workers: A challenge for post-apartheid health sector transformation. Drug Alcohol Depend. 2000; 59 (2):199-206.

10. Partanen J. Failures in alcohol policy: Lessons from Russia, Kenya, Truk and history. Addiction 1993:88:129S-134S.

11. Pisa PT, Loots DT, Nienaber C. Alcohol metabolism and the health hazards associated with alcohol abuse in a South African context: A narrative review. S Afr J Clin Nutr. 2008. (Submitted).

12. Pisa PT, Loots DT. The cardioprotective effect and putative mechanisms of light to moderate consumption of alcohol: A narrative review. S Afr J Clin Nutr. 2008. (Submitted).

13. Gopane RE, Pisa PT, Vorster HH, Kruger A, Margetts BM. Relationships of alcohol intake with biological health outcomes in an African population in transition: The Thusa study. S Afr J Clin Nutr. 2008. (Submitted).

14. Serfontein M, Venter C, Kruger A, Maclntyre U. Alcohol intake and micronutrient density in a population in transition: The Thusa study. S Afr J Clin Nutr. 2008. (Submitted).

15. Feinman L. Absorption and utilization of nutrients in alcoholism. Alcohol Health \& Res W. 1989;13(3):207-210.

16. Gruchow HW, Sobocinski KA, Barboriak JJ, Scheller, JG. Alcohol consumption, nutrient intake and relative body weight among US adults. Am J Clin Nutr. 1985;42(2):289-295.

17. Colditz GA, Giovannucci E, Rimm EB, et al. Alcohol intake in relation to diet and obesity in women and men. Am J Clin Nutr. 1991;54 (1):49-55.

18. Sato M, Lieber CS. Hepatic vitamin A depletion after chronic ethanol consumption in baboons and rats. J Nutr. 1981;111:2015-2023.

19. De Gaetano G, Di Castelnuovo A, Donati MB, lacoviello L. The Mediterranean lecture:Wine and thrombosis - from epidemiology to physiology and back. Pathophysiol Haemo T. 2003;33(5/6):466-471.

20. Valenzuela CF. Alcohol and neurotransmitter interactions. Alcohol Health Res W. 1997;21(2):144-147.

21. Jernigan DH, Monteiro M, Room R, Saxena S. Towards a global alcohol policy: Alcohol, public health and the role of WHO. Bulletin of the World Health Organization 2000;78(4):491-499.

22. Willis J. Drinking crisis: Change and continuity in cultures of drinking in sub-Saharan Africa. Afr J Drug Alcohol Stud. 2006;5(1):1-15.

23. Trice HM, Roman PM. Spirits and demons at work: Alcohol and other drugs on the job, 2nd ed. Ithaca, New York: Cornell University Press; 1978

24. Roman PM. Job characteristics and the identification of defiant drinking. J Drug Issues 1981;Summer:357-364.

25. Ducharme LJ, Martin JK. Unrewarding work, coworker support, and job satisfaction. Work Occupation 2000;27:223-243

26. Rose-Innes 0. Drugs don't work at work. City Press 2007 February 25:31.

27. Pienaar J, Rothmann S. Suicide ideation in the South African Police Service. S Afr J Psychol 2005;35(1):58-72.

28. Republic of South Africa. Liquor Act No. 59 of 2003. Gazette No. 26294. Pretoria: Government Printers: 2004.

29. Mphi M. Female alcoholism problems in Lesotho. Addiction 1994;89:945-949.

30. West MO. Liquor and libido: "Joint drinking" and the politics of sexual control in colonial Zimbabwe, 1920s-1950s. J Soc His. 1997;30(3):645-667.

31. Department of Social Development. National Drug Master Plan 2005-2010. Pretoria. (Unpublished.)

32. Morojele NK, Kachieng'a MA, Mokoko E, et al. Alcohol use and sexual behaviour among risky drinkers and bar and shebeen patrons in Gauteng province, South Africa. Soc Sci Med. 2006;62(1):217-227.

33. Unger, JB, Kipke, MD, Simon, TR, et al. Pathways: Causes and Consequences. Parity 2001;14(8):27-29.

34. Mallet S, Rosenthal D, Keys D. Young people, drug use and family conflict: Pathways into homelessness. Adolescence 2005;28:185-199.

35. Maree A. Criminogenic risk factors for youth offenders. In: Bezuidenhout C, Joubert S, editors. Child and youth misbehaviour in South Africa: A holistic view. 1st ed. Pretoria: Van Schaik, 2003; p. 43-63.

36. Strijdom JL. A drug policy and strategy for Namibia. DPhil dissertation. Mmabatho: University of Bophuthatswana; 1992

37. Bezuidenhout FJ. Substance abuse and addiction: Drugs and alcohol. In: Bezuidenhout FJ, editor. A reader on selected social issues. 3rd ed. Pretoria: Van Schaik, 2004; p. 127-128.

38. World Health Organization. Global status report on alcohol. Geneva: Department of Mental Health and Substance Abuse, WHO; 2004.

39. Bezuidenhout FJ. Divorce. In: Bezuidenhout FJ, editor. A reader on selected social issues. 3rd ed. Pretoria: Van Schaik, 2004; 15-30

40. Gallant DM. Unemployment and alcohol consumption. Alcohol Clin Exp Res. 1993;17(3):722-723.

41. Statistics South Africa. Labour force survey P0210, 2006 [cited 2007 April 14]. Available from http:// www.statssa.gov.za, p9.

42. Ettner SL. Measuring the human cost of a weak economy: Does unemployment lead to alcohol abuse? Soc Sci Med 1997;44(2):251-260

43. Obot IS. The measurement of drinking patterns and alcohol consumption in Nigeria. J Subst Abuse 2000;12(1-2):169-181

44. Jewkes R, Levin J, Penn-Kekana L. Risk factors for domestic violence: Findings from a South African cross sectional study. Soc Sci Med. 2002;55(9):1603-1617.

45. Parry CDH, Louw A, Plüddemann A. Drugs and crime in South Africa: The MRC/ISS 3-Metros Arrestee Study (Phase 3). Cape Town: Institute for Security Studies, Medical Research Council; 2004.

46. Boles SM, Miotto K. Substance abuse and violence a review of the literature. Aggress and Violent Be 2003;8:155-174

47. Rasool S, Vermaak K, Pharaoh R, Louw A, Stavrou A. Violence against women: A national survey. Pretoria: Institute for Social Security Studies; 2002 .

48. Olley BO, Seedat S, Gxamza F, Reuter H, Stein OJ. Determinants of unprotected sex among HIV-positive patients in South Africa. AIDS Care 2005;17(1):1-9.

49. Jacobs M, Shung-King M, Smith C, editors. South African Child Gauge 2005. Cape Town: Children's Institute, University of Cape Town; 2005.

50. Kalichman SC, Simbayi LC, Cain D, Jooste S. Alcohol expectancies and risky drinking among men and women at high-risk for HIV infection in Cape Town South Africa. Addict Behav. 2007;32(10):2304-2310.

51. Germain CB. Social work practice in health care: An ecological perspective. New York: Columbia University Press; 1980.

52. Department of Social development. Policy on the Management of Substance Abuse. March 2007:1-2 (Unpublished.)

53. Brysiewicz P. Trauma in South Africa. Int J Trauma Nurs. 2001;7(4):129-132

54. Agarwal DP. Cardioprotective effects of light-moderate consumption of alcohol: A review of putative mechanisms. Alcohol 2002;37(5):409-415.

55. Van Heerden IV, Parry CDH. If you drink alcohol, drink sensibly. S Afr J Clin Nutr. 2001:14(3):S71-S77. 